\title{
Reactive Diffusion Bonding Between Commercially Pure Titanium and 304 Stainless Steel Using Nickel Interlayer
}

\author{
Sukumar KUNDU, Mainak GHOSH and Subrata CHATTERJEE \\ Department of Metallurgy and Materials Engineering, Bengal Engineering College (Deemed University) Howrah-711103, W. \\ Bengal, India. E-mail: schatterjee46@yahoo.com
}

(Received on June 14, 2004; accepted in final form on August 5, 2004)

\begin{abstract}
Diffusion bonding was carried out between commercially pure titanium and 304 stainless steel using nickel as interlayer in the temperature range of $800-900^{\circ} \mathrm{C}$ for $5.4 \mathrm{ks}$ under $3 \mathrm{MPa}$ load in vacuum. The transition joints thus formed were characterized in optical and scanning electron microscopes. $\mathrm{TiNi}_{3}, \mathrm{TiNi}_{\mathrm{N}} \mathrm{and} \mathrm{Ti}_{2} \mathrm{Ni}$ are formed at the $\mathrm{Ni}-\mathrm{Ti}$ interface whereas, $304 \mathrm{ss}-\mathrm{Ni}$ diffusion zone is free from intermetallic compounds at 800 and $850^{\circ} \mathrm{C}$ processing temperatures. At $900^{\circ} \mathrm{C}, \mathrm{Ni}-\mathrm{Ti}$ interface exhibits the presence of $\alpha-\beta$ Ti discrete islands in the matrix of $\mathrm{Ti}_{2} \mathrm{Ni}$ and the phase mixture of $\alpha$ - $\mathrm{Fe}+\lambda+\chi$ occurs at the ss-Ni interface. Nickel is able to inhibit the diffusion of Ti to $304 \mathrm{ss}$ side up to $850^{\circ} \mathrm{C}$; however, becomes unable to restrict the migration of $\mathrm{Ti}$ to stainless steel at $900^{\circ} \mathrm{C}$. Highest bond strength of $80 \%$ of that of titanium has been obtained for the diffusion couple processed at $850^{\circ} \mathrm{C}$ owing to the better coalescence of the mating surfaces and failure takes place from $\mathrm{Ni}-\mathrm{Ti}$ interface. At higher joining temperature, the formation of Fe-Ti intermetallics reduces the bond strength and failure in tensile loading occurs from ss-Ni interface.
\end{abstract}

KEY WORDS: diffusion bonding; intermetallic compounds; intermediate material.

\section{Introduction}

Diffusion bonding of commercially pure titanium (cp Ti) and 304 stainless steel (304 ss) has emerged as an improved fabrication technique for producing primary and secondary components for application in nuclear, aerospace and chemical industries. ${ }^{1,2)}$ However, direct bonding of these materials promotes residual stress at the interface region caused by mismatch of thermal expansions between bonding materials and the formation of the intermetallic phases in the diffusion zone. ${ }^{3)}$

The interdiffusion and structure-properties relationship study between cp Ti and 304 ss exhibit that atomic migration of chemical species across the bond line promotes the formation of $\sigma, \chi, \lambda, \mathrm{FeTi}, \beta$-Ti and $\mathrm{Fe}_{2} \mathrm{Ti}_{4} \mathrm{O}$ phases in the reaction zone. ${ }^{4-6)}$ All these brittle intermetallics impair the mechanical properties of the transition joints. Consequently, diffusion bonding of these two materials using intermediate material is increasing importance. In this context, Nickel can be considered as an useful intermediate material for its satisfactory corrosion resistance. Ni has substantial extent of solid solubility in iron and in Ni-stainless steel diffusion couple no intermetallic formation has been reported. ${ }^{7)}$ However, an ordered compound of $\mathrm{Ni}-\mathrm{Cr}$ is formed at $22-32$ at $\% \mathrm{Cr}$ at $\sim 600^{\circ} \mathrm{C}$ and another compound of $\mathrm{Fe}-\mathrm{Ni}$ occurs for $74-84 \mathrm{at} \% \mathrm{Ni}$ at $\sim 500^{\circ} \mathrm{C}^{8,9)}$ On the other hand, binary phase diagram of Ni-Ti shows that, the mode of intermetallics formation changes from $\mathrm{Ti}_{2} \mathrm{Ni}$ to $\mathrm{TiNi}_{3}$ via TiNi with increasing Ni content. ${ }^{10,11)}$ It is also established that, $\mathrm{Ni}-\mathrm{Ti}$ intermetallic phases have higher plasticity than that of Fe-Ti intermetallics.

The informations concerning the diffusion bonding of $\mathrm{cp}$ $\mathrm{Ti}$ and 304 ss using $\mathrm{Ni}$ as an interlayer is scanty and makes it difficult to optimize the processing parameters to obtain a joint of satisfactory quality. Moreover, it has been illustrated earlier that, direct bonding between these dissimilar materials results in maximum bond strength of $\sim 70 \%$ of that of titanium. ${ }^{12)}$ Hence, the present investigation aims at improving the bond strength further with the use of interlayer. The bonding temperature was varied to observe its effect on the interface microstructure, which in turn will alter the strength of the diffusion bonds.

\section{Experimental}

The chemical compositions and room temperature tensile properties of commercially pure titanium and 304 stainless steel are given in Tables 1 and $\mathbf{2}$ respectively. Both of them were received in the form of rod having $20 \mathrm{~mm}$ diameter. From the base materials, cylinder of $15 \mathrm{~mm}$ diameter $\times$ $30 \mathrm{~mm}$ length was machined. The faying surfaces of the samples were prepared by metallographic technique with the surface roughness of $\sim 2.5 \mu \mathrm{m} .300 \mu \mathrm{m}$ thick nickel foil (purity $99.5 \mathrm{at} \%$ ) was used as intermediate material and both the surfaces was polished using $1 \mu \mathrm{m}$ diamond. The assembly was placed in a fixture under $3 \mathrm{MPa}$ uniaxial load, applied along the longitudinal direction of the specimen and was inserted in the chamber. Diffusion bonding was carried out at the temperatures of 800,850 and $900^{\circ} \mathrm{C}$ for $5.4 \mathrm{ks}$ in $(6-8) \times 10^{-5}$ mbar vacuum. Heating was done at 
Table 1. Chemical compositions of the base metals (wt $\%)$.

\begin{tabular}{|c|c|c|c|c|c|c|c|c|c|c|c|c|}
\hline Alloy & $\mathbf{C}$ & $\mathbf{F e}$ & $\mathbf{T i}$ & $\mathbf{M n}$ & $\mathbf{S i}$ & $\mathbf{S}$ & $\mathbf{P}$ & $\mathbf{C r}$ & $\mathbf{N i}$ & $\mathbf{O}$ & $\mathbf{N}$ & $\mathbf{H}$ \\
\hline $\mathrm{cp} \mathrm{Ti}$ & 0.02 & 0.10 & Bal & - & - & - & - & - & - & 0.15 & 0.02 & 0.0011 \\
\hline $304 \mathrm{ss}$ & 0.06 & Bal & - & 1.38 & 0.37 & 0.013 & 0.03 & 18.15 & 8.50 & - & 0.005 & - \\
\hline
\end{tabular}

Table 2. Tensile properties of the base metals at room temperature.

\begin{tabular}{|c|c|c|c|}
\hline Alloy & $\begin{array}{c}\text { 0.2\% proof stress } \\
\text { (MPa) }\end{array}$ & $\begin{array}{c}\text { Ultimate tensile strength } \\
\text { (MPa) }\end{array}$ & $\begin{array}{c}\text { Fracture } \\
\text { elongation (\%) }\end{array}$ \\
\hline $\mathrm{cp} \mathrm{Ti}$ & 205 & 319 & 23 \\
\hline $304 \mathrm{ss}$ & 740 & 822.5 & 42 \\
\hline
\end{tabular}
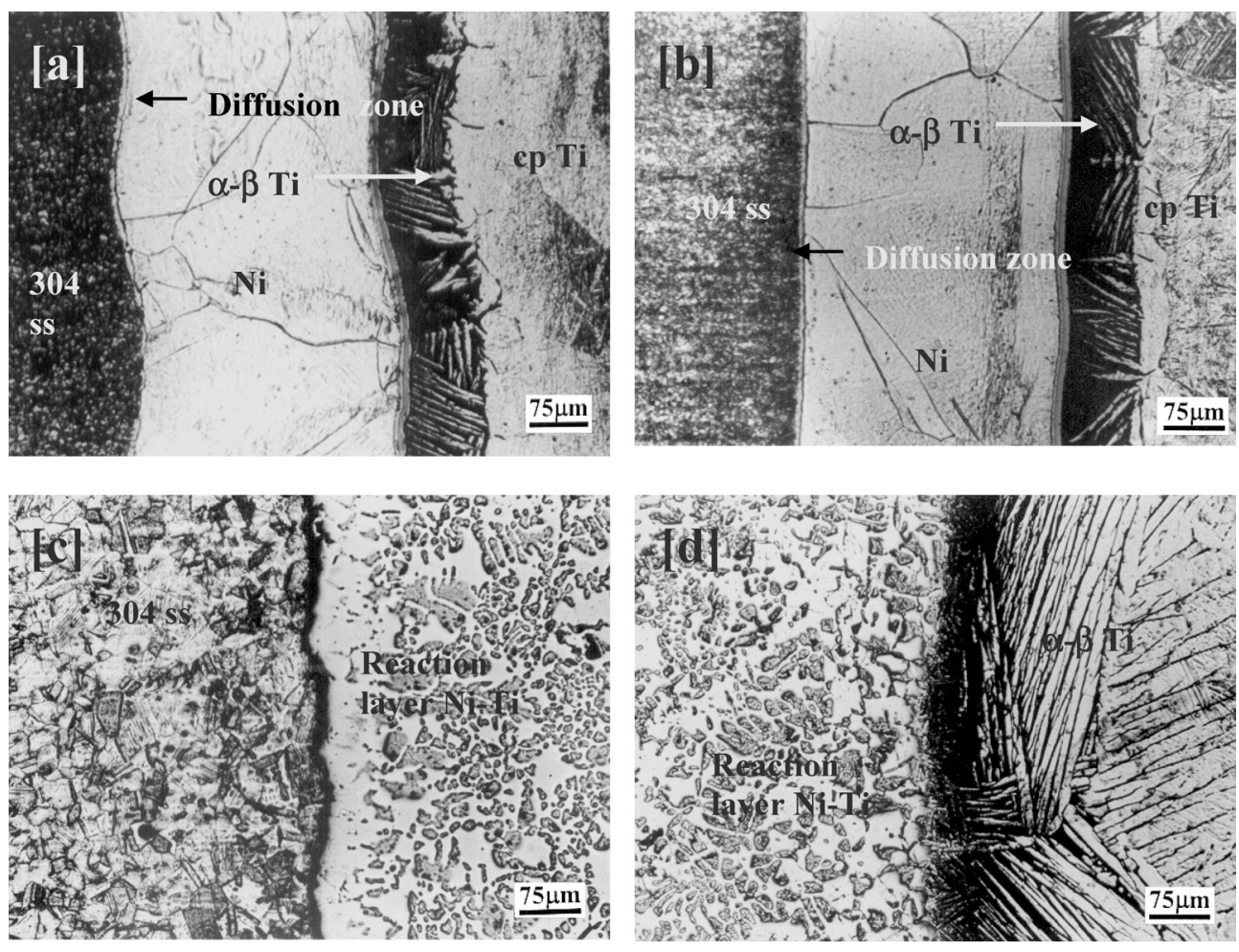

Fig. 1. Optical microstructure of the diffusion bonded assemblies joined at a) $800^{\circ} \mathrm{C}$, b) $850^{\circ} \mathrm{C}$, c) $900^{\circ} \mathrm{C}, 304 \mathrm{ss}-\mathrm{Ni}$ interface, d) $900^{\circ} \mathrm{C}, \mathrm{Ni}-\mathrm{Ti}$ interface.

the rate of $14^{\circ} \mathrm{C} / \mathrm{min}$ at the time of processing and after the operation the sample was allowed to cool in vacuum.

From the bonded couples, a transverse section was taken and prepared by conventional grinding and polishing technique. The titanium side was etched with an aqueous solution $(85 \mathrm{~mL})$ containing $\mathrm{HNO}_{3}(8 \mathrm{~mL})$ and $\mathrm{HF}(4 \mathrm{~mL})$. The stainless steel was etched by a mixture of $\mathrm{HNO}_{3}(10 \mathrm{~mL})$, $\mathrm{HCl}(40 \mathrm{~mL})$ and glycerol $(50 \mathrm{~mL})$. A solution consisting of glacial acetic acid $(50 \mathrm{~mL})$ and concentrate $\mathrm{HNO}_{3}(50 \mathrm{~mL})$ was used for etching pure nickel. The structural changes at both the interfaces, were observed in a light microscope. Finer structure details in the diffusion zone were revealed in scanning electron microscope using back-scattered mode (SEM-BSE). The composition of the reaction layers was determined in atomic percent using energy dispersive spectroscope. Tensile properties of the transition joints were evaluated in a tensile testing machine (Instron 4204) at a crosshead speed of $5 \times 10^{-2} \mathrm{~mm} / \mathrm{min}$ at room temperature. Cylindrical tensile specimens were machined as per ASTM specification (Vol. 03.01 E8M-96) with gauge diameter and length of 4 and $20 \mathrm{~mm}$ respectively. The interface was at the center of the gauge length. Four samples were tested at each process parameter to check the reproducibility of results. The presence of intermetallic phases on the fracture surfaces was confirmed by X-ray diffraction technique using copper target. The scanning span of $20-80^{\circ}$ with a step size of $0.01^{\circ}(=2 \theta)$ was used during diffraction study.

\section{Results and Discussion}

The optical microstructure of the bonded assemblies is shown in Fig. 1. From the photographs, it is observed that, certain amount of diffusion occurs between the interlayer and the two substrates. The stainless steel-nickel bonding interface is planar in nature and a thin diffusion layer was revealed for the processing temperatures of 800 and $850^{\circ} \mathrm{C}$. At the same joining temperatures the Ti-Ni interface is characterized by the presence of a lightly shaded reaction zone and the Widmanstatten $\alpha-\beta$ Ti structure. As a $\beta$-stabilizing element, nickel atoms, after migration in titanium lattice lowers the eutectoid transformation temperature of titanium and the acicular $\alpha-\beta$ Ti occurs from the decomposi- 

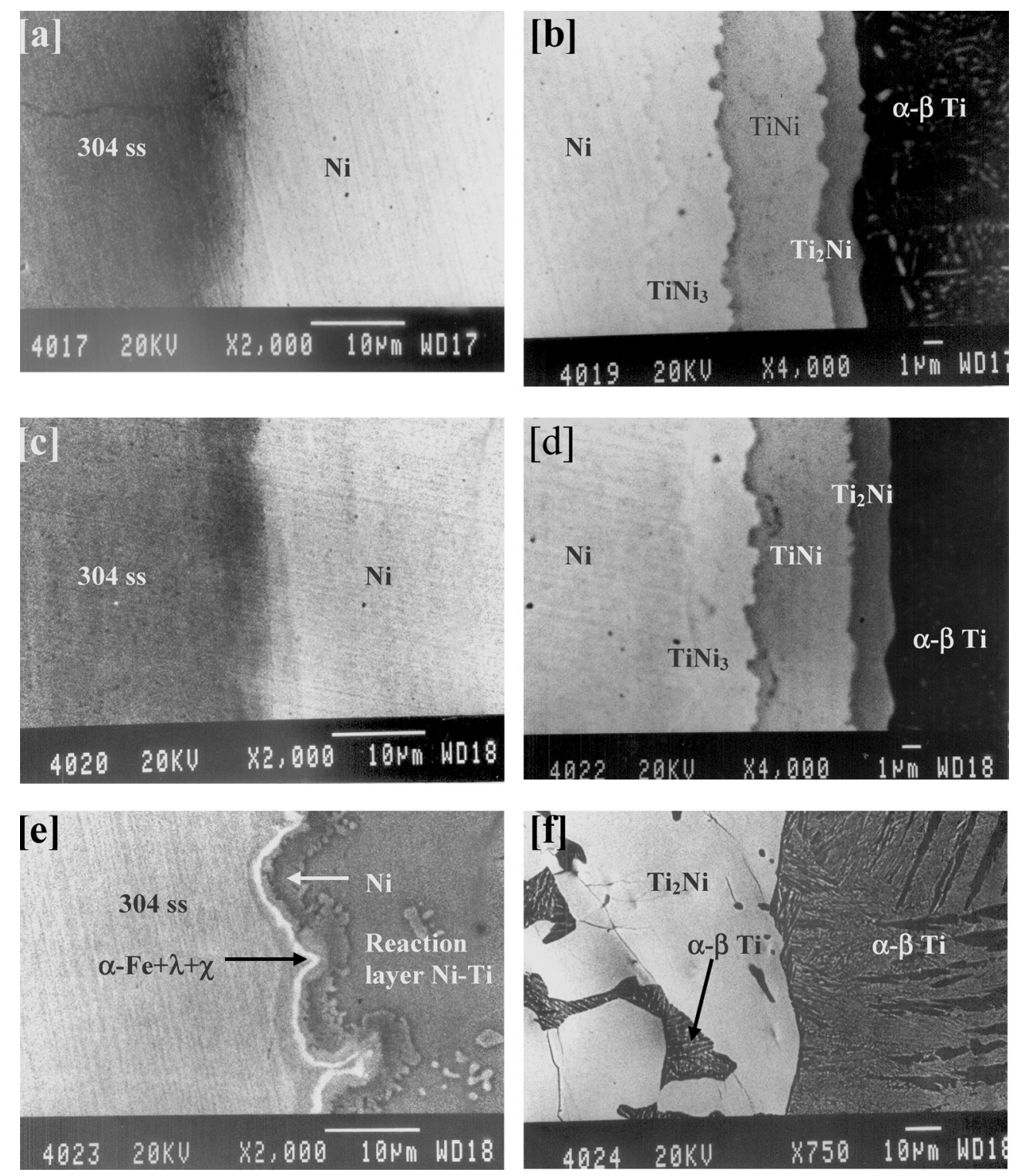

Fig. 2. SEM-BSE images of the transition joints processed at a) $800^{\circ} \mathrm{C}, 304 \mathrm{ss}-\mathrm{Ni}$ interface, b) $800^{\circ} \mathrm{C}, \mathrm{Ni}-\mathrm{Ti}$ interface, c) $850^{\circ} \mathrm{C}, 304 \mathrm{ss}-\mathrm{Ni}$ interface, d) $850^{\circ} \mathrm{C}$, Ni-Ti interface, e) $900^{\circ} \mathrm{C}, 304 \mathrm{ss}-\mathrm{Ni}$ interface, f) $900^{\circ} \mathrm{C}, \mathrm{Ni}-\mathrm{Ti}$ interface.

tion of $\beta$-Ti during cooling. ${ }^{13,14)} \mathrm{A}$ rise in processing temperature to $900^{\circ} \mathrm{C}$ leads to form deeply shaded diffusion zone at both the interfaces. The total diffusion zone at the $\mathrm{Ni}-\mathrm{ss}$ interface is smaller than the Ni-Ti interface. At 800 $900^{\circ} \mathrm{C}$, nickel and stainless steel both have fcc crystallography and being the close packed structure, the extent of diffusion of chemical species is limited. On the contrary, below $882^{\circ} \mathrm{C}$, Ti has two-phase structure i.e. $\alpha($ hcp $)+$ $\beta$ (bcc) and above $\beta$-transus it transforms to beta titanium. Owing to more open crystallography of bcc structure, nickel atoms can travel a longer distance in titanium matrix with respect to titanium in nickel lattice. ${ }^{15)}$

An increment in the joining temperature from 800 to $850^{\circ} \mathrm{C}$ results in grain growth of nickel interlayer $(\sim 128$ and $\sim 174 \mu \mathrm{m}$ at 800 and $850^{\circ} \mathrm{C}$ respectively) and at $900^{\circ} \mathrm{C}$ shaded islands $(\sim 21 \mu \mathrm{m})$ appear within the nickel matrix.

The SEM-BSE images of the transition joints are given in Fig. 2. Both Ni-ss and $\mathrm{Ni}-\mathrm{Ti}$ interfaces are resolved at higher magnification. The composition of the chemical species was determined near the two bond lines.

In the mutual diffusion layer at stainless steel-nickel in- terface, the composition changes gradually for $\mathrm{Fe}, \mathrm{Cr}$ and Ni. For 800 and $850^{\circ} \mathrm{C}$ joining temperatures, the diffusion zone is free from reaction products and the observation is in agreement with the earlier investigation. ${ }^{3)}$ Presence of $\mathrm{Fe}(\sim 6.8-10.7)$ and $\mathrm{Cr}(\sim 1.5-3.4)$ in the $\mathrm{Ni}$ side indicates substantial diffusion of the two alloying elements at the bonding temperatures of $800-850^{\circ} \mathrm{C}$ to nickel side. Similarly, Ni also migrates to the 304 ss substrate in adequate quantity ( 28.4-44.9) at the same temperature range. When the bonding temperature is enhanced to $900^{\circ} \mathrm{C}$, a marked change has been noticed in ss-Ni interface. The region is characterized by the presence of a bright reaction product containing $\mathrm{Ti}(\sim 12), \operatorname{Cr}(\sim 21.2), \mathrm{Ni}(\sim 2.6)$ and $\mathrm{Fe}(\mathrm{bal})$. Nickel concentration is low enough to form any nickel bearing intermetallic; hence ignoring the effect of nickel, from the ternary isotherm of $\mathrm{Fe}-\mathrm{Cr}-\mathrm{Ti}$, it can be predicted that the region contains the phase mixture of $\alpha$ $\mathrm{Fe}+\lambda+\chi$ having $\sim 1.1 \mu \mathrm{m}$ width (Fig. 2(e)). ${ }^{16,17)}$ This continuous bright phase is embedded in a lightly shaded region which is depleted in $\mathrm{Ni}(\sim 5.4)$ and $\mathrm{Ti}(\sim 4)$ and enriched with $\mathrm{Cr}(\sim 24.7)$ and $\mathrm{Fe}(\mathrm{bal})$. Adjacent to the lightly shaded 
region, the deeply shaded zone indicates the existence of pure $\mathrm{Ni}(\sim 90)$ containing $\mathrm{Fe}, \mathrm{Cr}$ and $\mathrm{Ti}$ in solid solution.

At the $\mathrm{Ni}-\mathrm{Ti}$ interface, for $800-850^{\circ} \mathrm{C}$ processing temperature three distinct reaction layers have been observed (Figs. 2(b) and 2(d)). At the nickel side the faint area contains $\mathrm{Ni}(\sim 79.8-80.3)$ and $\mathrm{Ti}(\mathrm{bal})$ and corresponds to $\mathrm{TiNi}_{3}$ intermetallic. ${ }^{10)}$ Close to titanium base metal the deeply shaded region is enriched with $\operatorname{Ti}(\sim 59.7)$ and depleted in $\mathrm{Ni}$ (bal); hence indicates the formation of $\mathrm{Ti}_{2} \mathrm{Ni}$ intermetallic compound. ${ }^{18)}$ Between $\mathrm{TiNi}_{3}$ and $\mathrm{Ti}_{2} \mathrm{Ni}$, another lightly shaded reaction band TiNi is present having the composition of $\mathrm{Ti}(\sim 42.4)$ and $\mathrm{Ni}(\mathrm{bal}){ }^{10)}$ Increment in diffusion welding temperature to $900^{\circ} \mathrm{C}$ results in disappearance of layer wise reaction products at $\mathrm{Ni}-\mathrm{Ti}$ interface; rather between the pure nickel and titanium, the area is the combination of bright and shaded regions. The average composition of the bright matrix is $\mathrm{Ti}(\sim 52.3), \mathrm{Ni}(\sim 37.6), \mathrm{Fe}(\sim 8)$ and $\mathrm{Cr}$ (bal) and that of the shaded island is $\operatorname{Cr}(\sim 3.5), \operatorname{Fe}(\sim 3.9)$, $\mathrm{Ni}(\sim 8.5)$ and $\mathrm{Ti}($ bal $)$. Hence, the former is $\mathrm{Ti}_{2} \mathrm{Ni}$ intermetallic compound and the latter is the phase aggregate of Widmanstatten $\alpha-\beta$ titanium.

From the electron micrographs, it is evident that, the rise in joining temperature encourages profuse diffusion of chemical species across the bond line. The thickness of $\mathrm{Ti}_{2} \mathrm{Ni}$, TiNi and $\mathrm{TiNi}_{3}$ is $\sim 3.4, \sim 4.8$ and $\sim 1.7 \mu \mathrm{m}$ at $800^{\circ} \mathrm{C}$ and increases to $\sim 3.7,4.9$ and $2.1 \mu \mathrm{m}$ at $850^{\circ} \mathrm{C}$ processing temperature respectively. At ss- $\mathrm{Ni}$ interface the same trend is also observed as the presence of $\mathrm{Fe}$ and $\mathrm{Cr}$ in nickel matrix and enrichment of nickel concentration in stainless steel side increase at $850^{\circ} \mathrm{C}$ in comparison to $800^{\circ} \mathrm{C}$.

From the results of energy dispersive spectroscopy for the transition joint processed at $900^{\circ} \mathrm{C}$, it has been observed that, at this bonding temperature the lowering of yield stress of the interlayer results in irregular shaped residual nickel at the $304 \mathrm{ss}-\mathrm{Ni}$ interface. Moreover, $300 \mu \mathrm{m}$ thick nickel intermediate layer is unable to block the diffusion of titanium to stainless steel side and this phenomenon has been divulged by the existence of $\alpha-\mathrm{Fe}+\lambda+\chi$ phase mixture at the $\mathrm{Ni}$-ss reaction layer. The enhanced atomic transport of $\mathrm{Ti}$ at $900^{\circ} \mathrm{C}$ is also responsible for prevailing non-equilibrium situation to cause the absence of $\mathrm{Ni}-\mathrm{Ti}$ intermetallics as continuous layer at the $\mathrm{Ni}-\mathrm{Ti}$ interface; rather acicular $\alpha-\beta$ itanium occurs in the form of islands surrounded by $\mathrm{Ti}_{2} \mathrm{Ni}$ phase.

The tensile properties of the diffusion-annealed samples are illustrated in Fig. 3. At low bonding temperature like $800^{\circ} \mathrm{C}$, both the bond strength and the breaking strain of the diffusion couple is low because at this temperature yield strength of the bonded material is still high. The deformation of the base metals at the interfaces and the extent of diffusion of alloying elements is limited at both the interfaces. Moreover, diffusion of $\mathrm{Ni}$ and $\mathrm{Ti}$ promotes intermetallics formation in the diffusion zone and lowers the bond strength. During tensile loading failure takes place from $\mathrm{Ni}-\mathrm{Ti}$ interface and $\mathrm{X}$-ray diffraction analysis indicates the formation of $\mathrm{NiTi}_{2}, \mathrm{Ni}_{3} \mathrm{Ti}$ and $\mathrm{NiTi}$ at the fracture surfaces (Figs. 4(a) and 4(b)). With the rise in diffusion annealing temperature to $850^{\circ} \mathrm{C}$, the bond strength is enhanced as the plastic deformation of the master alloy increases owing to the lowering in the yield stress of the same. On the other hand, $850^{\circ} \mathrm{C}$ processing temperature

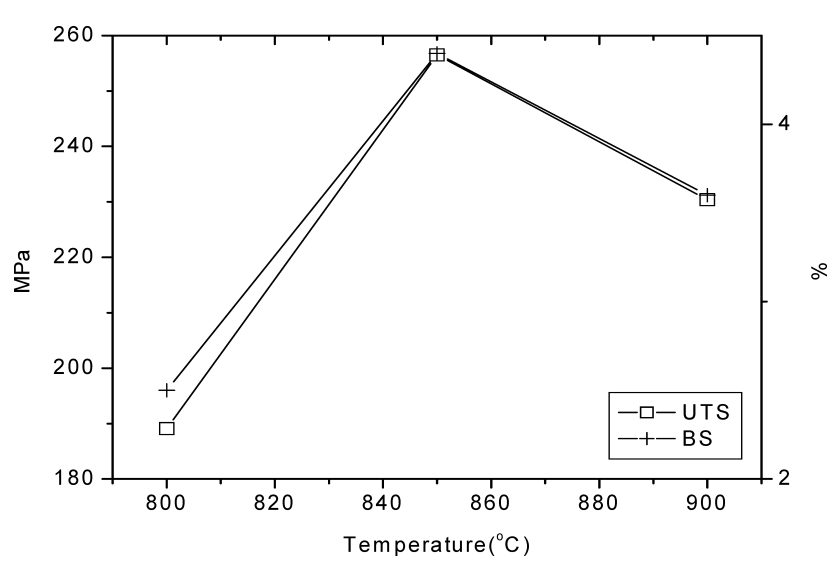

Fig. 3. Tensile properties of the diffusion bonded assemblies.

also promotes atomic diffusivity of the chemical species, which in turn is accountable for the increment in the width of the reaction products at the Ni-Ti interface. Though the volume fraction of $\mathrm{Ni}-\mathrm{Ti}$ intermetallic phases emanates at $850^{\circ} \mathrm{C}$ with respect to $800^{\circ} \mathrm{C}$ bonding temperature yet, the plastic collapse of the faying surface asperities steers the betterment in bond strength and ductility of the transition joints. The UTS value exhibits a substantial improvement in bond duality (in terms of UTS, $80 \%$ of that of titanium) with respect to earlier reported values of directly bonded $\mathrm{cp}$ Ti-304 ss joint. ${ }^{2,4,12,18)}$ Fracture takes place once again through Ni-Ti interface as the XRD analysis exhibits the occurrence of $\mathrm{NiTi}_{2}, \mathrm{Ni}_{3} \mathrm{Ti}$ and $\mathrm{NiTi}$ in the reaction zone (Figs. 4(c) and 4(d)). So, in the temperature range of 800$850^{\circ} \mathrm{C}$, the presence of $\mathrm{Ni}-\mathrm{Ti}$ intermetallics at nickel-titanium interface plays a key role for failure in tensile testing.

A further rise in processing temperature to $900^{\circ} \mathrm{C}$ decreases the bond strength and ductility of the diffusion bonded couples. SEM-BSE images (Figs. 2(e) and 2(f)) unveil that, at the $\mathrm{Ni}-\mathrm{Ti}$ interface no layer wise intermetallic is formed yet, ss-Ni interface is characterized by the presence of $\alpha-\mathrm{Fe}+\lambda+\chi$ phase aggregate. $\lambda$ phase is a solid-solution of $(\mathrm{Fe}, \mathrm{Cr})_{2} \mathrm{Ti}$ having hexagonal structure. Both of them are hard and very brittle in comparison to Ni-Ti intermetallics. So, failure occurs through this phase mixture and the fracture surface is denoted by the manifestation of $\alpha-\mathrm{Fe}$, $\sigma, \chi, \mathrm{Fe}_{2} \mathrm{Ti}$ and $\mathrm{Cr}_{2} \mathrm{Ti}$ compounds. The occurrence of $\sigma$ phase has not been found in SEM-BSE micrographs perhaps due to its small volume fraction. The $\sigma$ phase principally contains $\mathrm{Fe}$ and $\mathrm{Cr}$. Ti migration in 304 ss lattice decreases the activity of $\mathrm{Cr}$. Hence, diffusion takes place down the activity gradient rather than the concentration gradient. Cr enrichment occurs due to uphill diffusion of the same and during cooling the chromium enriched region transforms to the $\mathrm{s}$ phase. ${ }^{15)}$ The formation of $\alpha$-Fe in 304 ss matrix supports the findings of previous investigation where, it has been stated that, $\sim 0.8 \mathrm{at} \%$ of $\mathrm{Ti}$ in austenite matrix promotes the formation of bcc ferrite. ${ }^{20)}$ It can be also inferred that $\mathrm{Fe}-\mathrm{Ti}$ intermetallics are more pernicious than Ni-Ti intermetallics in detoriating the bond strength and breaking strain of the diffusion bonded joints.

\section{Conclusions}

Solid state diffusion bonding was carried out in vacuum 

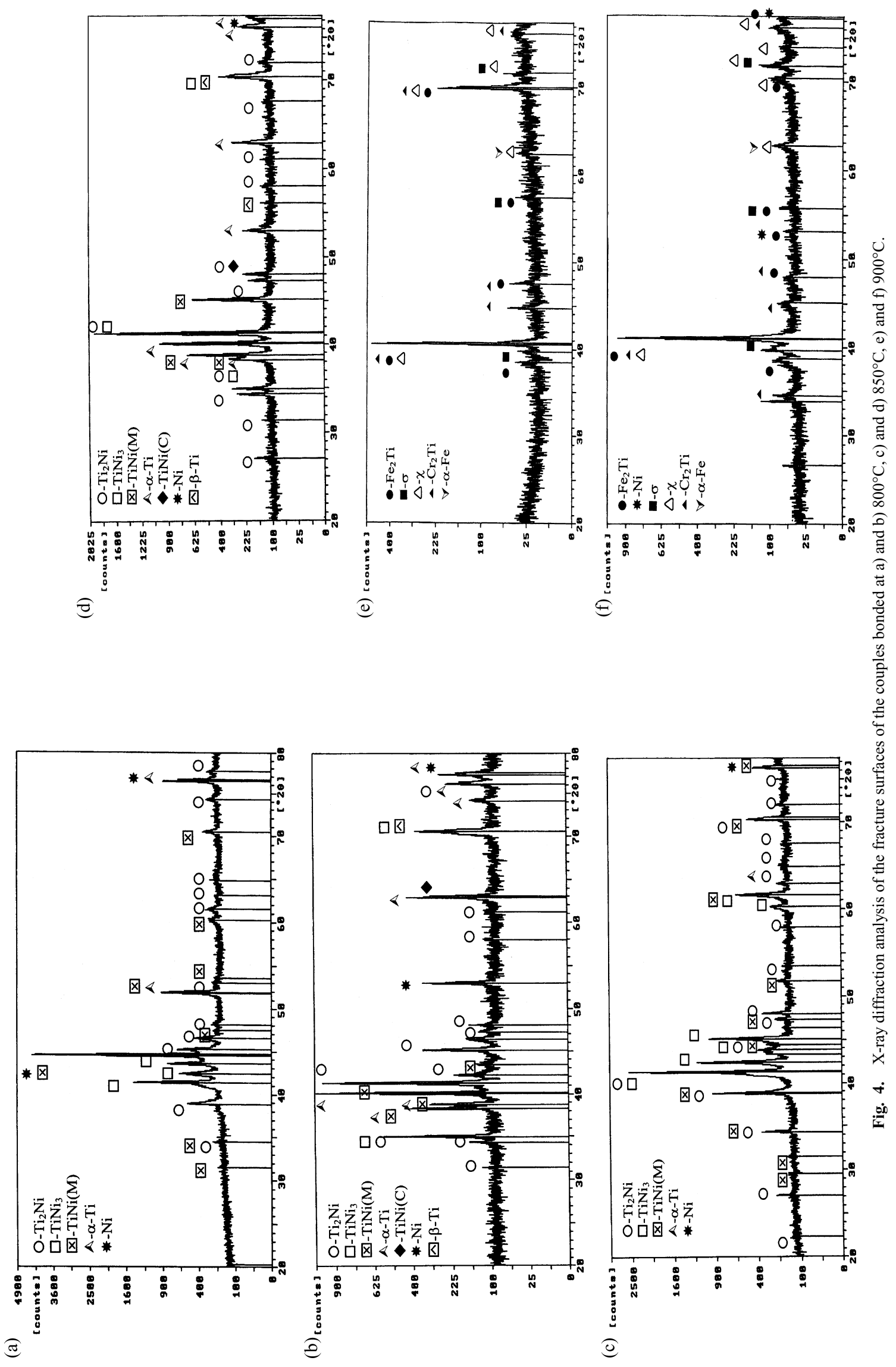
between commercially pure titanium and 304 stainless steel using $300 \mathrm{~mm}$ nickel as interlayer. Processing parameters were $800-900^{\circ} \mathrm{C}$ temperature, $5.4 \mathrm{ks}$ time and $3 \mathrm{MPa}$ load. Characterization of the transition joints reveals the fallowing:

$304 \mathrm{ss}-\mathrm{Ni}$ interface is free from any reaction product at the joining temperatures of 800 and $850^{\circ} \mathrm{C}$ yet, $\alpha-\mathrm{Fe}+\lambda+\chi$ phase aggregates was formed in the diffusion zone of the same region at $900^{\circ} \mathrm{C}$ bonding temperature.

At Ni-Ti interface inter-diffusion between $\mathrm{Ni}$ and $\mathrm{Ti}$ encourages layer wise formation of $\mathrm{Ni}_{3} \mathrm{Ti}, \mathrm{NiTi}$ and $\mathrm{Ni}_{2} \mathrm{Ti}$ in the diffusion zone at $800-850^{\circ} \mathrm{C}$ joining temperature; however their presence has not been found at $900^{\circ} \mathrm{C}$ bonding temperature. Between pure nickel and titanium, $\alpha-\beta$ Ti exists as discrete islands in the matrix of $\mathrm{Ti}_{2} \mathrm{Ni}$ at $900^{\circ} \mathrm{C}$.

A rise in processing temperature promotes atomic migration of chemical species across both the bond lines; yet, up to $850^{\circ} \mathrm{C}$ joining temperature $300 \mu \mathrm{m} \mathrm{Ni}$ interlayer can completely inhibit the diffusion of $\mathrm{Ti}$ to $304 \mathrm{ss}$ side. However, at $900^{\circ} \mathrm{C}$ titanium atoms can cross the nickel matrix to form $\mathrm{Fe}-\mathrm{Ti}$ intermetallics at ss-Ni interface.

Highest bond strength $(\sim 257 \mathrm{MPa})$ with substantial ductility has been obtained for the diffusion couple processed at $850^{\circ} \mathrm{C}$ due to the better coalescence of mating surfaces and failure occurs from Ni-Ti interface. Similar trend has been observed for the specimens bonded at $800^{\circ} \mathrm{C}$ though, UTS is lower than the previous value owing to the limited plastic deformation of mating surface asperities. With the rise in joining temperature to $900^{\circ} \mathrm{C}$ the fracture occurs from ss-Ni interface due to formation of brittle $\mathrm{Fe}-\mathrm{Ti}$ intermetallics resulting in decrease in bond strength.

\section{REFERENCES}

1) P. He, J. H. Zhang and X. Q. Li: Mater. Sci. Technol., 17 (2001), 1158.

2) M. Ghosh and S. Chatterjee: Mater. Charact., 48 (2002), 393.

3) H. Kato, S. Abe and T. Tomizawa: J. Mater. Sci., 32 (1997), 5225.

4) M. Ghosh, K. Bhanumurthy, G. B. Kale and S. Chatterjee: J. Nucl. Mater, 322 (2003), 235.

5) A. Changing and J. Zhangpeng: J. Less-Common Met., 162 (1990), 315.

6) B. Aleman, I. Guitterrez and J. J. Urcola: Mater. Sci. Technol., 9 (1993), 633.

7) G. R. Kamat: Weld. J., (1998), 44.

8) K. P. Gupta: Phase Diagram of Ternary Nickel Alloys, Part 1, ed. by T. Mukherjee, Indian Institute of Metals, Calcutta, (1990), 3.

9) T. B. Massalski: Binary Alloy Phase Diagrams, 2nd ed., Vol. 2, ASM International, Materials Park, Ohio, (1996), 1735.

10) S. Hinotani and Y. Ohmori: Trans. Jpn. Inst. Met., 29 (1988), 116.

11) T. B. Massalski: Binary Alloy Phase Diagrams, 2nd ed., Vol. 2, ASM International, Materials Park, Ohio, (1996), 2874.

12) M. Ghosh, K. Bhanumurthy, G. B. Kale, J. Krishnan and S. Chatterjee: ISIJ Int., 44 (2004), 388.

13) M. Eroglu, T. I. Khan and N. Orhan: Mater. Sci. Technol., 18 (2002), 68.

14) M. Ghosh, S. Chatterjee and B. Mishra: Mater. Sci. Eng. A, $\mathbf{A 3 6 3}$ (2003), 268.

15) M. Ghosh and S. Chatterjee: Mater. Sci. Eng. A, A358 (2003), 152.

16) V. Raghavan: Phase Diagrams of Ternary Iron Alloys, Part 1, ASM International, Materials Park, Ohio, (1987), 43.

17) M. Ghosh, A. Laik, K. Bhanumurthy, G. B. Kale, J. Krishnan and S. Chatterjee: "Evolution of interface microstrucvture and strength properties in the titanium-stainless steel diffusion bonded transition joints", Mater. Sci. Technol., in press.

18) P. He, J. Zhang, R. Zhou and X. Li: Mater. Charact., 43 (1999), 287.

19) H. Kato, M. Shibata and K. Yoshikawa: Mater. Sci. Technol., 2 (1986), 405.

20) G. B. Kale, R. V. Patil and P. S. Gawde: J. Nucl. Mater, 257 (1998), 44. 